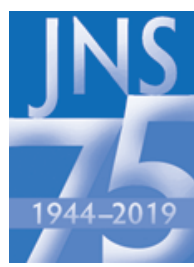

\title{
Medulloblastoma in the age of molecular subgroups: a review
}

\author{
JNSPG 75th Anniversary Invited Review Article
}

\author{
Kyle Juraschka, MD, ${ }^{1-4}$ and Michael D. Taylor, MD, $\mathrm{PhD}^{1-4}$ \\ ${ }^{1}$ Division of Neurosurgery; ${ }^{2}$ The Arthur and Sonia Labatt Brain Tumor Research Centre, The Hospital for Sick Children; and \\ Departments of ${ }^{3}$ Laboratory Medicine and Pathobiology and ${ }^{4}$ Surgery, University of Toronto, Ontario, Canada
}

\begin{abstract}
Medulloblastoma is the most common pediatric malignant brain tumor. Advances in molecular profiling have uncovered significant heterogeneity among medulloblastomas and led to the identification of four distinct subgroups (wingless [WNT], sonic hedgehog [SHH], group 3, and group 4) that represent distinct disease entities in both underlying biology and clinical characteristics. The rapidly expanding repertoire of tools to study developmental and cancer biology is providing a wealth of knowledge about these embryonal tumors and is continuously refining the understanding of this complex cancer. In this review, the history of discovery in medulloblastoma is discussed, setting a foundation to outline the current state of understanding of the molecular underpinnings of this disease, with a focus on genomic events that define the aforementioned subgroups and evolving areas of focus, such as the cell of origin of medulloblastoma and medulloblastoma subtypes. With these recent discoveries in mind, the current state of medulloblastoma treatment and clinical trials is reviewed, including a novel risk stratification system that accounts for the molecular biomarkers of patients with a high risk for refractory disease. Lastly, critical areas of focus for future basic science and clinical research on this disease are discussed, such as the complexities of medulloblastoma metastases and recurrence as well as the priorities and strategies to implement in future clinical trials.
\end{abstract}

https://thejns.org/doi/abs/10.3171/2019.5.PEDS18381

KEYWORDS medulloblastoma; oncology; neurooncology; genomics; metastasis

$\mathrm{M}$ EDULLOBLASTOMA is the most common malignant (WHO grade IV) brain tumor of childhood and is an embryonal lesion thought to arise from progenitor cell populations present during early brain development. ${ }^{17,31,67}$ Medulloblastoma is currently treated with maximal safe resection, chemotherapy, and craniospinal radiation. Despite such aggressive multimodal therapy, approximately $30 \%$ of patients eventually succumb to this disease, and survivors cope with the long-term side effects of treatment that have significant impacts on their quality of life. $12,18,20,35,41,42,66$

Initial descriptions of medulloblastoma date back to Harvey Cushing, who initially described medulloblastoma as a subset of gliomas (Fig. 1). ${ }^{2,11,57}$ He detailed many key features of these tumors, including their tendency to arise from the cerebellar vermis and to exhibit leptomeningeal metastasis. ${ }^{11}$ Along with neuropathologist Percival Bailey, Cushing described medulloblastoma histopathologically as containing numerous mitoses, small round nuclei, and minimal cytoplasm. ${ }^{2}$ The two recognized that medullo- blastoma cells resembled undifferentiated cells present in embryonal stages and posited that medulloblastoma arose from "medulloblasts," multipotent stem cells thought to be present in the neural tube. ${ }^{2,26,32,57}$ While no such single primitive cell type exists, Cushing and Percival's foundational work in defining the clinical characteristics, operative technique, and histopathology of this tumor formed our basic understanding of medulloblastoma, which is now being refined in the molecular era. ${ }^{57}$

While some early medulloblastoma patients were treated with radiation sporadically, the first landmark change in the management of these tumors came in 1953, when a study of 27 patients with medulloblastoma demonstrated significantly improved survival after receiving craniospinal radiation. ${ }^{44,57}$ Routine craniospinal radiation improved survival to approximately $60 \%$. $^{44}$ The next intriguing progression in our understanding of this disease occurred in 1973 in a study in which the authors proposed that medulloblastoma be classified as a primitive neuroectodermal tumor (PNET) because of histological similarities and a

ABBREVIATIONS GTR = gross-total resection; NTR = near-total resection; PFS = progression-free survival; $\mathrm{SHH}$ = sonic hedgehog; WNT = wingless.

SUBMITTED May 14, 2019. ACCEPTED May 28, 2019.

INCLUDE WHEN CITING DOI: 10.3171/2019.5.PEDS18381. 


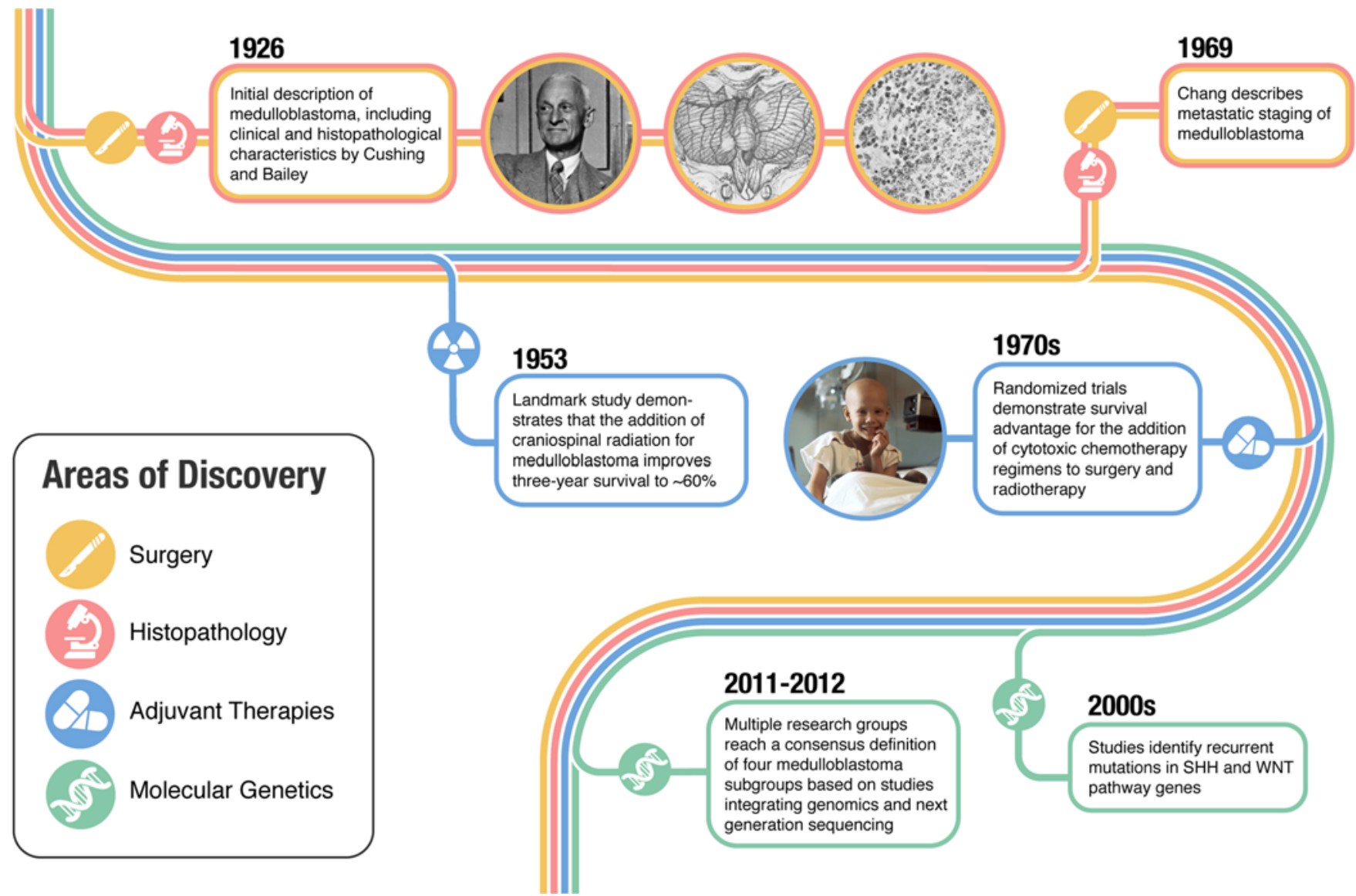

FIG. 1. Timeline of key discoveries in medulloblastoma, culminating in the definition of the four molecular subgroups. Photograph of Dr. Harvey Williams Cushing. Source: https://wellcomecollection.org/works/nzkqj47t?wellcomelmagesUrl=/indexplus/image/ V0027585.html. Courtesy of The Wellcome Trust, CC BY 4.0 license (https://creativecommons.org/licenses/by/4.0/deed.en). Sketch and photomicrograph reproduced from Cushing $\mathrm{H}$ : Experiences with the cerebellar medulloblastomas. Acta Pathologica Microbiologica Scandinavica 7:1-86, 1930. Public domain. Photograph of a young girl receiving chemotherapy. Source: https:/l visualsonline.cancer.gov/details.cfm?imageid=2192. Photographer: Bill Branson. Public domain. National Cancer Institute AV Number: AV-8503-3438. Figure is available in color online only.

hypothesis that medulloblastoma and other PNETs arise from undifferentiated cells in the subependymal zone. ${ }^{16}$ Finally, the addition of cytotoxic chemotherapy regimens as standard of care, starting with trials in the 1970 s, improved the 5-year survival risk for average-risk disease to $70 \%-80 \%$ and for high-risk disease to $60 \%-65 \% .5,20,41$

Rapid advances in molecular genetics over the past two decades have provided significant advancements in our understanding of medulloblastoma. This tumor entered the molecular era, beginning with gene expression array studies demonstrating that medulloblastoma is a distinct entity from other embryonal central nervous system tumors. ${ }^{47}$ Multiple independent groups performed transcriptional profiling on medulloblastoma samples and reached consensus on four distinct molecular subgroups: wingless (WNT), sonic hedgehog (SHH), group 3, and group 4. ${ }^{8,25,37,52,63}$ Molecular subgrouping has already influenced the design of contemporary clinical trials and refined preclinical studies of medulloblastoma, and these subgroups were adopted into the 2016 WHO classification of tumors of the central nervous system. ${ }^{31}$ The expanding wealth of molecular data from patient samples has started to allow further refinement of these subgroups, with numerous subtypes of medulloblastoma being recognized. ${ }^{7,36,59}$

In this review, our current understanding of this fascinating disease will be reviewed, including the molecular underpinnings of this disease, risk stratification, treatment protocols, and the landscape of current clinical trials. Subsequently, key areas of future inquiry in basic science and clinical trials will be discussed.

\section{Epidemiology}

Medulloblastoma accounts for approximately $20 \%$ of all childhood brain tumors and $63 \%$ of intracranial embryonal tumors. ${ }^{40}$ These tumors can arise throughout childhood and into adulthood with an overall annual incidence of approximately 5 cases per 1 million in the pediatric population. ${ }^{40}$ Seventy percent of medulloblastomas occur in children under the age of 10 , with incidence peaking in children 1-4 and 5-9 years of age. ${ }^{23,40}$ Overall, medulloblastoma is more common in males, affecting approximately 1.7 times more males than females, ${ }^{23,40}$ although sex predilection as well as age-specific incidence 


\begin{tabular}{|c|c|c|c|c|c|}
\hline & Subgroup & WNT & SHH & Group 3 & Group 4 \\
\hline \multirow{8}{*}{ 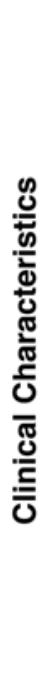 } & $\%$ of Cases & 10 & 30 & 25 & 35 \\
\hline & Age at Diagnosis & & & $\div$ & 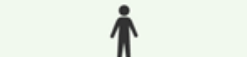 \\
\hline & Gender Ratio (M:F) & $1: 1$ & $1: 1$ & $2: 1$ & $3: 1$ \\
\hline & Anatomic Location & & & & \\
\hline & Histology & $\begin{array}{c}\text { Classic, } \\
\text { Rarely LCA }\end{array}$ & $\begin{array}{l}\text { Desmoplastic, } \\
\text { Classic, LCA }\end{array}$ & Classic, LCA & Classic, LCA \\
\hline & $\begin{array}{l}\text { Metastasis at } \\
\text { Diagnosis (\%) }\end{array}$ & $5-10$ & $15-20$ & $40-45$ & $35-40$ \\
\hline & Recurrence Pattern & $\begin{array}{l}\text { Rare; Local } \\
\text { or metastatic }\end{array}$ & Local & Metastatic & Metastatic \\
\hline & Prognosis & Very good & $\begin{array}{l}\text { Infants good, } \\
\text { others intermediate }\end{array}$ & Poor & Intermediate \\
\hline \multirow{5}{*}{ 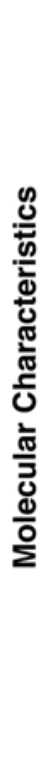 } & $\begin{array}{l}\text { Proposed Cell } \\
\text { of Origin }\end{array}$ & $\begin{array}{l}\text { Progenitor cells } \\
\text { in the lower } \\
\text { rhombic lip }\end{array}$ & $\begin{array}{c}\text { Granule precursors } \\
\text { of the external } \\
\text { granule layer }\end{array}$ & $\begin{array}{c}\text { Neural } \\
\text { stem cells }\end{array}$ & $\begin{array}{l}\text { Unipolar } \\
\text { brush cells }\end{array}$ \\
\hline & $\begin{array}{l}\text { Recurrent Gene } \\
\text { Amplifications }\end{array}$ & - & $\begin{array}{c}\text { MYCN } \\
\text { GLI1 or } G L 12\end{array}$ & $\begin{array}{l}\text { MYC } \\
\text { MYCN } \\
\text { OTX2 }\end{array}$ & $\begin{array}{l}\text { SNCAIP } \\
\text { MYCN } \\
\text { OTX2 } \\
\text { CDK6 }\end{array}$ \\
\hline & Recurrent SNVs & $\begin{array}{l}\text { CTNNB1 } \\
\text { DDX3X } \\
\text { SMARCA4 } \\
\text { TP53 }\end{array}$ & $\begin{array}{c}\text { PTCH1 } \\
\text { TERT } \\
\text { SUFU } \\
\text { SMO } \\
\text { TP53 }\end{array}$ & $\begin{array}{l}\text { SMARCA4 } \\
\text { KBTBD4 } \\
\text { CTDNEP1 } \\
\text { KMT2D }\end{array}$ & $\begin{array}{l}\text { KDM6A } \\
\text { ZMYM3 } \\
\text { KTM2C } \\
\text { KBTBD4 }\end{array}$ \\
\hline & $\begin{array}{c}\text { Cytogenetic Events } \\
\square \text { Gain } \quad \text { Loss }\end{array}$ & 6 & $\begin{array}{c}3 q, 9 p \\
9 q, 10 q, 17 p\end{array}$ & $\begin{array}{c}1 q, 7,18 \\
8,10 q, 11,16 q \\
i 17 q\end{array}$ & $\begin{array}{l}\text { 7, 18q } \\
8,11 p, x \\
i 17 q\end{array}$ \\
\hline & $\begin{array}{l}\text { Other Recurrent } \\
\text { Genetic Events }\end{array}$ & - & - & $\begin{array}{l}\text { GFI1 and GFI1B } \\
\text { enhancer hijacking }\end{array}$ & $\begin{array}{c}\text { PRDM6, GFI1, } \\
\text { and GFI1B } \\
\text { enhancer hijacking }\end{array}$ \\
\hline
\end{tabular}

Age:

FIG. 2. The molecular subgroups of medulloblastoma, based on data from the following references. ${ }^{36,37,61} \mathrm{LCA}=$ large cell/anaplastic; SNV = single-nucleotide variant. Figure is available in color online only.

vary by subgroup (Fig. 2). ${ }^{61}$ Medulloblastoma is far more rare in adulthood, with a reported incidence of 0.05 cases per 100,000 population. ${ }^{40}$

Primary risk factors for the development of medulloblastoma include hereditary cancer predisposition syndromes. Germline mutations in WNT signaling pathway genes, such as APC mutations, which occur in Turcot syndrome, can predispose to WNT medulloblastoma. ${ }^{70} \mathrm{SHH}$ medulloblastomas may be initiated by germline mutations in PTCH1 (Gorlin syndrome), SUFU, TP53 (Li-Fraumeni syndrome), or $S M O$ (Curry-Jones syndrome). ${ }^{6,60,64,70} \mathrm{Nu}$ merous other cancer predisposition syndromes have been associated with medulloblastoma, although with a lower risk of medulloblastoma development than the aforementioned syndromes associated with WNT and SHH tumors. ${ }^{70}$

\section{Molecular Subgroups of Medulloblastoma WNT}

WNT subgroup medulloblastomas account for approximately $10 \%$ of all medulloblastomas. ${ }^{61}$ These tumors typically occur in children over the age of 4 and adolescents and affect an equal number of males and females. ${ }^{61}$ They are typically located midline with involvement of the brainstem or in the cerebellar peduncle and cerebello- 
pontine angle cistern. ${ }^{46}$ The WNT subgroup is associated with an excellent prognosis $(>95 \%$ survival at 5 years in pediatric patients), is rarely metastatic at diagnosis (5\%$10 \%$ of cases), and rarely recurs., ${ }^{9,61}$

WNT medulloblastoma is thought to arise from progenitor cells in the lower rhombic lip of the developing brainstem. ${ }^{17,67}$ Approximately $90 \%$ of WNT tumors contain a mutation in $C T N N B 1$, which encodes $\beta$-catenin. ${ }^{36}$ This mutation causes the WNT signaling pathway to be constitutively active, driving expression of WNT responsive genes that promote tumor proliferation. ${ }^{61}$ Mutations in the $A P C$ tumor suppressor gene account for the majority of WNT tumors that lack $C T N N B 1$ mutations. ${ }^{61,70}$ Other recurrently mutated genes identified in this subgroup include DDX3X (36\%), SMARCA4 (19\%), TP53 (14\%), CSNK2B (14\%), PIK3CA (11\%), and EPHA7 (8\%). ${ }^{22,36,48,54}$ Monosomy 6 is also characteristic of WNT tumors $(80 \%-85 \%$ of cases) and typically coincides with $C T N N B 1$ mutations. ${ }^{36}$ Aside from monosomy 6, WNT tumors have balanced genomes and rarely contain copy number aberrations. ${ }^{37}$

Building on the classification of medulloblastoma into subgroups, recent integrated analysis of DNA methylation, gene expression, copy number alterations, and clinical data has suggested the existence of subtypes of medulloblastoma within each subgroup. 7 Using gene expression and methylation array data, Cavalli et al. suggested the existence of two WNT subtypes: WNT $\alpha$ and WNT $\beta$. The WNT $\alpha$ subtype primarily occurred in children and $98 \%$ of these cases had monosomy 6 , whereas the WNT $\beta$ subtype occurred in older children and adults and infrequently (29\%) had monosomy 6 . $^{7}$

\section{SHH}

The SHH subgroup has a balanced sex ratio and a bimodal peak age incidence, most often occurring in infants and adults, accounting for two-thirds of medulloblastoma cases in these age groups. ${ }^{24,61}$ Approximately $30 \%$ of medulloblastomas are classified as $\mathrm{SHH}$ tumors. ${ }^{61}$ They characteristically arise in the cerebellar hemispheres, rather than the midline location characteristic of other subgroups. ${ }^{46}$ Outcomes in this subgroup vary according to clinical (age and metastatic status) and molecular (MYCN amplification and TP53 mutation status) characteristics. ${ }^{7,50}$

SHH tumors are thought to arise from granule cell precursors of the external granule layer. ${ }^{17,67}$ The majority of these tumors contain germline or somatic mutations or copy number alterations in the SHH signaling pathway, leading to constitutively activated $\mathrm{SHH}$ signaling, driving tumor development and progression. Commonly mutated or deleted SHH genes include PTCH1 (43\%) and SUFU $(10 \%) .{ }^{36}$ Activating mutations of SMO (9\%) and amplifications in GLII or GLI2 $(9 \%)$ and MYCN (7\%) are also frequently observed. ${ }^{36}$ In addition, recurrent alterations in the TP53 signaling pathway (9.4\%) and the PI3K pathway $(10 \%)$ may also act as key drivers of tumorigenesis in this subgroup. ${ }^{39}$ TERT promoter mutations are also found in $39 \%$ of $\mathrm{SHH}$ tumors (including nearly all adult $\mathrm{SHH}$ cases). ${ }^{7,36}$ Frequently occurring cytogenetic events in this group include loss of chromosome $9 \mathrm{q}$ (causing loss of heterozygosity of PTCH1) and 10q (loss of SUFU). ${ }^{36}$

$\mathrm{Up}$ to four different $\mathrm{SHH}$ subtypes have been de- scribed.,56,59 One study of childhood (age 0-16 years) medulloblastoma defined two subtypes based on comprehensive molecular profiling: childhood (age 4.3 and older) and infant (under 4.3 years). ${ }^{59}$ Four $\mathrm{SHH}$ subtypes were described by Cavalli et al.: $\mathrm{SHH} \alpha, \mathrm{SHH} \beta, \mathrm{SHH} \gamma$, and

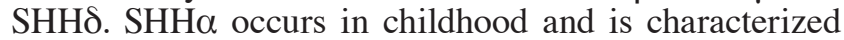
by frequent TP53 mutations and MYCN/GLI2 amplifications. ${ }^{7} \mathrm{SHH} \beta$ occurs in infants, is frequently metastatic, and is associated with a poor outcome compared to that with $\mathrm{SHH} \gamma$, which also occurs in infants and is associated with medulloblastoma with extensive nodularity (MBEN) histology. ${ }^{7}$ Finally, the SHHס subtype occurs in adults and is enriched for TERT promoter mutations.?

\section{Group 3}

Group 3 medulloblastoma has a male predominance and occurs nearly exclusively in infants and young children. ${ }^{61}$ This subgroup accounts for approximately $25 \%$ of all medulloblastoma cases and is associated with high rates of metastasis at diagnosis (40\%-45\%) and the worst survival outcomes of any subgroup (under $60 \%$ at 5 years). ${ }^{61}$ Radiographically, these tumors typically demonstrate a midline vermian location adjacent to the fourth ventricle. ${ }^{46}$

Group 3 tumors likely arise from a neural stem cell population. ${ }^{17,67}$ Unlike the $\mathrm{SHH}$ and WNT subgroup tumors, integrated molecular analyses have not identified a common driver pathway that defines the group 3 and group 4 subgroups. Nonetheless, a commonly recurring aberration is $M Y C$ amplification (17\%), an event that frequently co-occurs with PVT1-MYC fusions. ${ }^{36,39}$ Recurrent somatic mutations are rare in group 3 tumors, with only four genes mutated in over $5 \%$ of cases (SMARC4, KBTBD4, $C T D N E P 1$, and KMT2D). ${ }^{36}$ Small subsets of these tumors are driven by amplifications of $M Y C N(5 \%)$ and the transcription factor OTX2 (3\%). ${ }^{36}$ Enhancer hijacking events leading to the upregulation of $G F I 1$ and $G F I I B$ are present in $15 \%-20 \%$ of group 3 medulloblastomas and may also be important driver events in this subgroup. ${ }^{38}$ Cytogenetic events are abundant in this subgroup. Isochromosome $17 \mathrm{q}$ is present in $40 \%-50 \%$ of cases, and other common events are loss of chromosomes $8,10 \mathrm{q}$, and $16 \mathrm{q}$ and gain of $1 \mathrm{q}$, 7 , and $18 .{ }^{36}$

Several subtype classifications for group 3 medulloblastoma have emerged. One study outlined high-risk and low-risk subtypes using methylation data, in which the high-risk subgroup featured frequent $M Y C$ amplifications in infants and a hypomethylation phenotype. ${ }^{59}$ Another study defined three subtypes: $3 \alpha$ (occurring in infants and frequently metastatic but associated with a better outcome), $3 \beta$ (occurring in older children and featuring OTX2 gain, $D D X 31$ loss, and high $G F I 1 / G F I 1 B$ expression), and $3 \gamma$ (occurring in infants and associated with high rates of metastasis and $M Y C$ amplification). ${ }^{7}$

\section{Group 4}

Group 4 medulloblastoma accounts for $35 \%-40 \%$ of all medulloblastoma diagnoses. ${ }^{61}$ It typically occurs in childhood and adolescents and far more frequently in males (3:1 sex ratio) ${ }^{61}$ Anatomically, these tumors typically have a midline vermian location. ${ }^{46}$ Although this subgroup is 


\begin{tabular}{|c|c|c|c|c|}
\hline Risk Category & Low Risk & Standard Risk & High Risk & Very High Risk \\
\hline Survival (\%) & $>90$ & $75-90$ & $50-75$ & $<50$ \\
\hline \multirow{3}{*}{$\begin{array}{c}\text { Subgroup, } \\
\text { clinical and } \\
\text { molecular } \\
\text { characteristics }\end{array}$} & \multirow[t]{2}{*}{ Non-metastatic } & $\begin{array}{l}\text { Non-metastatic, } \\
\text { TP53 WT and no } \\
\text { MYCN amplification }\end{array}$ & \multirow{2}{*}{$\begin{array}{c}\text { One or both: } \\
\text { • Metastatic } \\
\text { - MYCN amplification }\end{array}$} & \multirow[t]{2}{*}{ TP53 Mutation } \\
\hline & & $\begin{array}{l}\text { Non-metastatic and no } \\
\text { MYC amplification }\end{array}$ & & \\
\hline & $\begin{array}{c}\text { Non-metastatic } \\
\text { and Chromosome } \\
11 \text { loss }\end{array}$ & $\begin{array}{l}\text { Non-metastatic and no } \\
\text { chromosome } 11 \text { loss }\end{array}$ & Metastatic & Metastatic \\
\hline
\end{tabular}

FIG. 3. Proposed risk stratification for noninfant medulloblastoma, based on data from the following reference. ${ }^{50}$ Box color represents the subgroup and the text reflects clinical and molecular criteria (WNT: blue, SHH: red, group 3: yellow, group 4: green). WT $=$ wild type. Figure is available in color online only.

also frequently metastatic (35\%-40\% at diagnosis), survival outcomes are intermediate in this subgroup and recurrences tend to occur late. ${ }^{51,61}$

The cell of origin of group 4 medulloblastoma has not been definitively established; however, these tumors appear to have transcriptional similarities to unipolar brush cells. ${ }^{67}$ Common somatic mutations are also rare in this subgroup. KDM6A, ZMYM3, KTM2C, and KBTBD4 are the most commonly mutated genes but occur in only $6 \%-9 \%$ of cases ${ }^{36}$ As in group 3 tumors, amplifications in $M Y C N$ and $O T X 2$ and enhancer hijacking-mediated overexpression of GFII and GFIIB are recurrent driver events in group 4 tumors. ${ }^{36}$ Other frequent events in this subgroup are $C D K 6$ amplification $(6 \%)$ and overexpression of PRDM6 via an enhancer hijacking event (17\%), which frequently occurs with SNCAIP duplication events. ${ }^{36} \mathrm{Cy}$ togenetic events include isochromosome 17q, gain of chromosomes 7 and 18q, and loss of 8q, 8p, 11p, and X. ${ }^{36,61}$

High-risk and low-risk subtypes were characterized by Schwalbe et al., in which the high-risk group was enriched for isochromosome 17q and had a 36\% 10-year survival, whereas the low-risk group had chromosome 11 loss and a 72\% 10-year survival. ${ }^{59}$ Cavalli et al. subdivided group 4 tumors into three subtypes. Molecular features associated with these subtypes include $M Y C N$ and $C D K 6$ amplification in group $4 \alpha, S N C A I P$ duplication in group $4 \beta$, and CDK6 amplification in group $4 \gamma^{7}$

\section{Risk Stratification}

Prior to the identification of medulloblastoma subgroups, patient risk stratification for the purposes of treatment allocation and in clinical trial design divided patients into average-risk and high-risk groups. ${ }^{50}$ This stratification system used age at diagnosis, metastatic stage, and extent of resection as the key criteria to determine the risk group. In this system, average-risk patients are those older than 3 years of age at diagnosis, without metastatic disease (M0 Chang stage), and with total or near-total resection (NTR; residual tumor volume $<1.5 \mathrm{~cm}^{3}$ ). ${ }^{18,41}$ Average-risk patients typically had $80 \%$ survival rates in contemporary studies. ${ }^{41}$ Patients not meeting the aforementioned criteria were classified as high risk, with survival rates ranging from $60 \%$ to $65 \% .12,20$

Recently, an updated risk stratification proposal for medulloblastoma patients ages 3-17 was developed (Fig. 3), taking into account subgroup status and select genetic and cytogenetic aberrations to more accurately predict outcome. ${ }^{50}$ This stratification system assigns patients to one of four risk groups: low risk ( $>90 \%$ survival), standard risk (75\%-90\% survival), high risk (50\%-75\% survival), and very high risk $(<50 \%$ survival $) .{ }^{50}$

\section{Treatment}

\section{Tumor Resection}

The importance of tumor resection was recognized by Cushing, who noted an increased survival time in patients who had undergone radical resection versus biopsy alone. ${ }^{11}$ The importance of the extent of resection has been revisited in observational studies over time, refining our understanding of how best to surgically manage these patients. These studies have generally demonstrated that NTR and gross-total resection (GTR) have similar outcomes, suggesting a general guiding principle of maximal safe resection. ${ }^{1}$ Recently, the benefit of extent of resection was reanalyzed while controlling for the molecular subgroup in a cohort of 787 patients. ${ }^{62}$ After controlling for subgroup across the entire cohort, there was a progressionfree survival (PFS) benefit with GTR over that with subtotal resection (STR; defined as residual tumor $\geq 1.5 \mathrm{~cm}^{3}$ ) but no benefit for PFS or overall survival (OS) with GTR over NTR (residual tumor $<1.5 \mathrm{~cm}^{3}$ ). ${ }^{62}$ In the analysis of PFS and OS for individual subgroups, only the patients with group 4 tumors appeared to have a PFS benefit with GTR over STR. ${ }^{62}$ To summarize, while GTR remains the ideal goal of surgery, similar outcomes can be expected in patients with minimal residual tumor, and surgeons must weigh the potential neurological morbidity of a more complete resection against leaving residual tumor. Of note, an important goal of surgery is obtaining sufficient tissue for histopathological diagnosis and molecular analysis. Given 
the spatial molecular heterogeneity within the primary tumor, multiregional tissue sampling during resection, especially of regions of residual tumor, is important to determine the ubiquity of genetic and epigenetic aberrations, aiding in the rational selection of targeted therapy.

The role of resection for locally recurrent medulloblastoma has not been rigorously investigated. Studies have suggested a benefit to repeat resection; however, these studies tend to have highly selected patients, and analyses accounting for molecular subgroup are lacking. ${ }^{3}$ Nonetheless, given the divergent evolution and clonal selection that occur throughout therapy, biopsy or repeat resection of recurrent tumor may provide molecular insights to guide therapy for recurrence. ${ }^{34}$

\section{Radiation Therapy}

In children older than 3-5 years of age, the current convention for radiotherapy involves radiation to the entire craniospinal axis in order to treat or provide prophylaxis against metastatic recurrence. Patients without metastatic disease who have had at least NTR of the primary tumor receive a 23.4-Gy dose of craniospinal radiation and a 54.0-Gy boost to the tumor bed..$^{12,41,42}$ Radiation strategies for patients who present with metastatic disease are more variable, with patients in most North American centers receiving a 36.0-Gy dose of craniospinal radiation, with a 54.0-Gy dose to the primary tumor bed and a 50.0- to 54.0-Gy boost to nodular metastatic deposits. ${ }^{12,18}$ In Europe, patients with metastases often receive radiotherapy following chemotherapy, in either conventional (single dose per day) or hyperfractionated (two doses per day) regimens. ${ }^{14}$ Current areas of investigation are establishing the efficacy of treatment de-escalation for WNT medulloblastoma and incorporating alternate radiation technologies, such as proton beam therapy in place of photon-based radiation. $^{72}$

\section{Chemotherapy}

Current chemotherapy regimens are primarily determined by the patient's age, suitability for radiotherapy, and risk category. In children over 3-5 years old who receive radiation and have NTR or GTR and no metastases, the current standard of care proposed by the Children's Oncology Group (COG) is a chemotherapy regimen starting with weekly vincristine concurrent with radiotherapy, followed by eight cycles of cisplatin, vincristine, and either cyclophosphamide or lomustine. ${ }^{41,43}$ The optimal chemotherapy regimen in patients categorized as high risk in the nonmolecular risk stratification system has not been defined; thus, there is more variability in chosen agents and number of cycles. For example, a recent COG trial used carboplatin and vincristine during radiotherapy, followed by six cycles of cyclophosphamide and vincristine, with some patients also receiving cisplatin. ${ }^{18}$ Other trials have investigated the use of intraventricular methotrexate and high-dose chemotherapy with autologous hematopoietic cell transplantation (HCT) ${ }^{68}$ In young children (under the ages of 3-5), in whom the neurological impairment caused by radiotherapy precludes its use, multi-agent chemotherapy is used to delay the use of radiotherapy. As in older patients with high-risk disease, clinical trials have also incorporated intrathecal methotrexate and high-dose myeloablative chemotherapy with autologous HCT for young children with medulloblastoma. ${ }^{58}$

\section{Side Effects of Therapy}

Trade-offs between the side effects of current therapies and the potential improved survival have caused survival rates to be relatively stagnant over the past three decades. ${ }^{20}$ Resection can be complicated by neurological deficits, particularly posterior fossa syndrome (cerebellar mutism), which occurs in approximately $25 \%$ of patients and characteristically manifests as difficulty with language production and emotional lability. ${ }^{28}$ Radiotherapy and cytotoxic chemotherapy, particularly in younger children, are associated with neurocognitive impairment, hearing loss (potentially exacerbated by cisplatin chemotherapy), short stature, pituitary hormone deficiency, cataracts, cerebrovascular disease (e.g., stroke, intracranial hemorrhage, cavernous malformations), and secondary malignancies. $^{18,53}$ These factors have significant impacts on the quality of life of medulloblastoma survivors and increase the urgency to identify more effective treatments to improve stagnant survival rates while also identifying therapies that reduce the long-term sequelae of current treatments.

\section{Landscape of Current Clinical Trials}

Many clinical trials currently underway have started to harness the insights provided by our improved understanding of the molecular underpinnings of medulloblastoma.

\section{Treatment De-Escalation for WNT Medulloblastoma}

Identification of the low-risk WNT subgroup spurred numerous trials investigating treatment de-escalation in children harboring these tumors, with the goals of reducing treatment-related toxicities, improving quality of life outcomes, and maintaining excellent survival rates. For example, clinical trials NCT02066220, NCT01878617, and NCT02724579 are studying reduced-dose craniospinal radiation and primary tumor bed boost in combination with reduced-dose chemotherapy. Another clinical trial, NCT02212574, investigating a treatment approach using chemotherapy and surgery without radiotherapy for these patients was suspended.

\section{Incorporating Targeted Therapies for SHH Medulloblastoma}

Inhibition of SHH signaling has long been recognized as a potential targeted therapy for medulloblastoma harboring genetic alterations in SHH pathway genes. ${ }^{30,55}$ Previous studies using vismodegib and sonidegib, competitive antagonists of the smoothened receptor, have demonstrated improved PFS in SHH medulloblastoma. . 30,55 Of note, many patients treated with SMO inhibition have developed treatment resistance over time, suggesting that monotherapy with these agents alone may be insufficient for durable remission. A proposed target downstream of SMO in the SHH pathway is CK2 inhibition, and a phase 1/2 trial using the CK2 inhibitor CX-4945 in recurrent SHH medulloblastoma is currently recruiting patients (NCT03904862). ${ }^{49}$ 
A

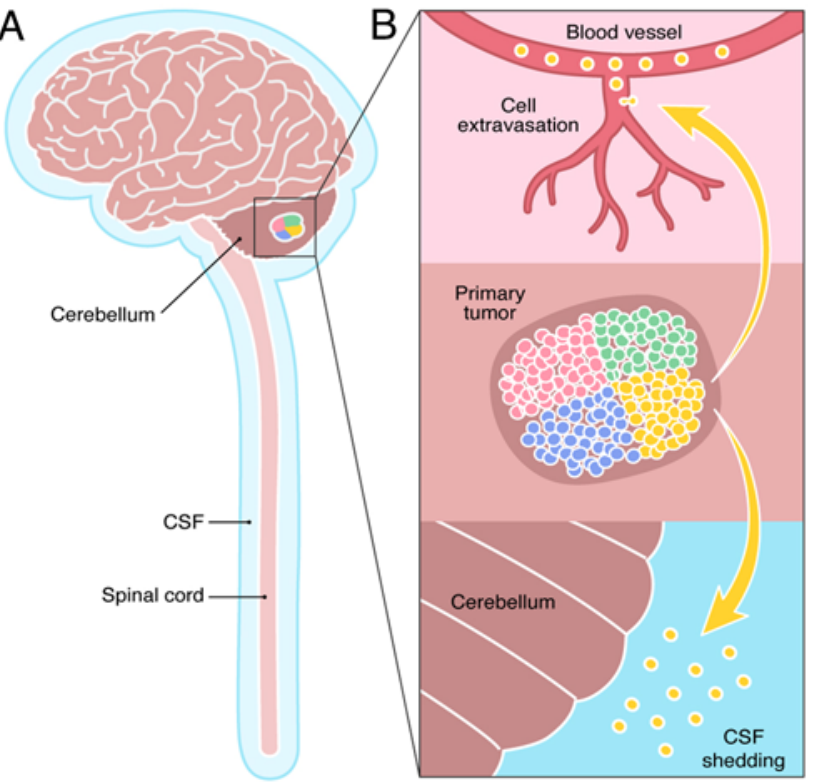

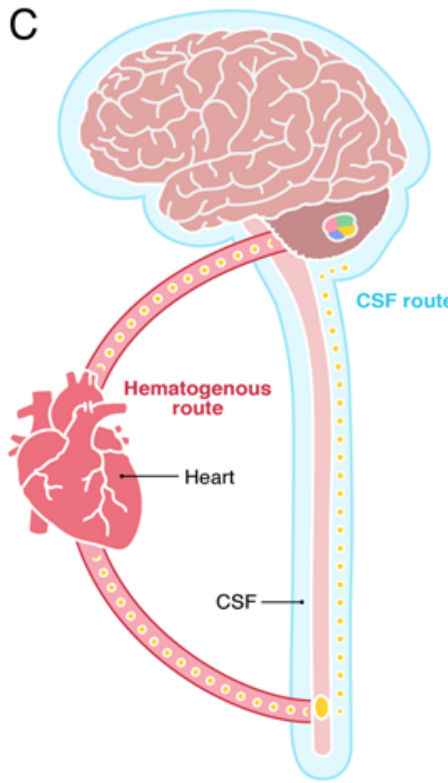

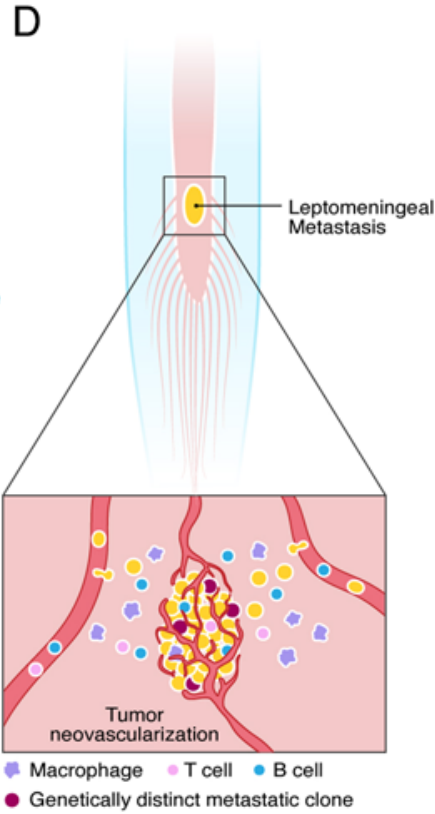

FIG. 4. Key features of medulloblastoma metastasis, based on data from the following references. ${ }^{15,71} \mathbf{A}$ : The primary tumor in the cerebellum is composed of distinct subclones, of which select clones may have metastatic potential. B: Metastatic clones may shed from the primary tumor into the CSF circulation or extravasate into local circulation. C: Metastatic cells transit via a CSF route or a hematogenous route to colonize distant leptomeningeal sites. D: Metastatic clones undergo further genetic divergence in the leptomeningeal niche and undergo complex interactions with the tumor microenvironment, including immune cell interaction and neovascularization. Copyright Azuravesta Design. Published with permission. Figure is available in color online only.

\section{Stratifying Patients by Subgroup and Disease Risk}

A multicenter trial currently underway (NCT01878617) provides a template for incorporating subgroup and risk stratification status into the trial design. The trial uses molecular subgroup (WNT, SHH, and non-WNT/non-SHH) and clinical and cytogenetic characteristics to stratify patients. Low-risk WNT patients receive reduced-intensity therapy, skeletally mature SHH patients receive vismodegib (in addition to standard of care treatment), and standard-risk and high-risk non-WNT/non-SHH patients are prioritized for treatment intensification with pemetrexed and gemcitabine.

\section{Priorities for Preclinical Research Improving Preclinical Models of Medulloblastoma}

While several preclinical models of medulloblastoma are available, recent advances in the understanding of medulloblastoma cell of origin and molecular subtype may help to guide the development of novel models of this disease, particularly group 3 and group 4, for which existing models that recapitulate human disease are lacking.7,25,34,67 Understanding of the cell of origin may aid in driving key genetic aberrations in the appropriate cell type and developmental context in preclinical models. Attempting to model medulloblastoma subtypes, rather than subgroups, may provide the opportunity to model important driver events that are common in a particular subtype but rare at a subgroup level. Refinement of preclinical models in this way may improve the likelihood of successful translation while also guiding proper inclusion criteria for subsequent clinical trials.

\section{Understanding Mechanisms of Recurrence and Treatment Resistance}

Patients with recurrent medulloblastoma following current standard of care treatment have dismal outcomes, with survival rates under $10 \%$ despite aggressive treatment approaches including repeat resection, re-irradiation, and various high-dose chemotherapy regimens. ${ }^{3,13,21}$ Recent work has started to reveal the complexity of medulloblastoma recurrence. One important insight is that the medulloblastoma molecular subgroup remains unchanged at recurrence. ${ }^{34}$ A limitation in studying disease recurrence to date is the limited number of available matched primary and recurrent patient samples, particularly for group 3 and 4 medulloblastomas, which tend to recur as distant metastases not amenable to resection or biopsy. Nonetheless, existing data have revealed that potentially actionable events in the primary tumor sample are often absent in recurrent tumor samples, suggesting that significant divergent evolution and clonal selection alter the drivers of tumorigenesis and maintenance in recurrence. ${ }^{34}$ Given the lack of human data, this is a key area that can be addressed in preclinical models to better understand common mechanisms of treatment resistance and recurrence and to identify new treatment strategies.

\section{Targeting Medulloblastoma Metastasis}

Medulloblastoma metastasis, which almost universally disseminates to the leptomeninges (Fig. 4), is a poor prognostic marker in nearly all medulloblastoma patients, except those with WNT medulloblastoma, where metastasis is exceptionally rare. ${ }^{50}$ Yet, little is known about the molecular programs necessary for medulloblastoma metastasis and survival in the leptomeningeal space, and there are no 
A

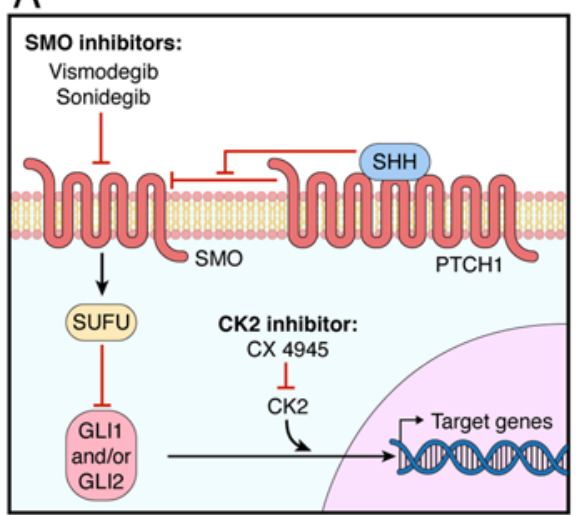

C

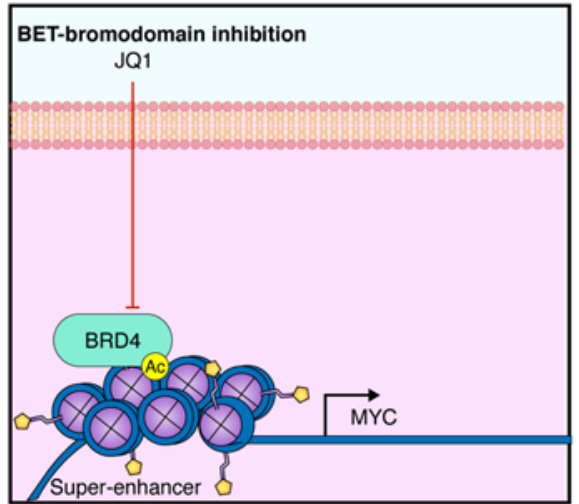

B

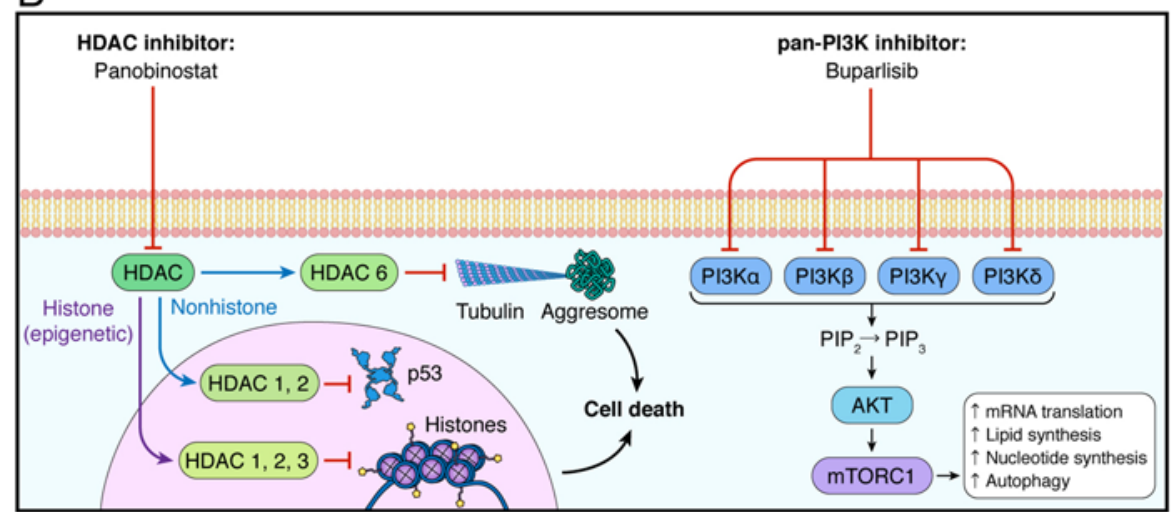

D

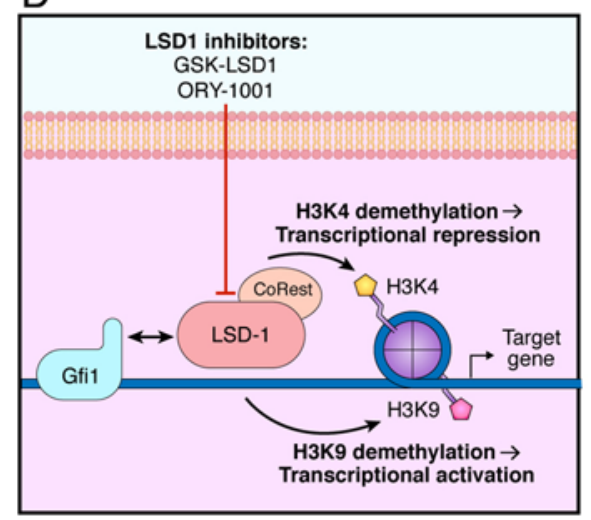

$\mathrm{E}$

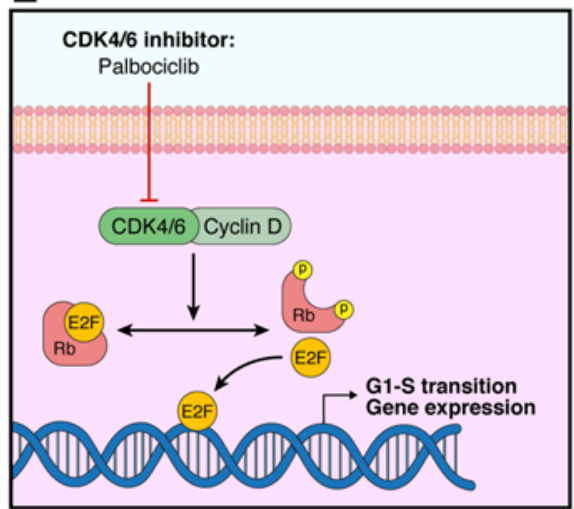

FIG. 5. Proposed targeted therapies in specific molecular subgroups of medulloblastoma, based on data from the following references. ${ }^{4,10,19,27,29,33,45,49,55,65,73}$ Inhibition of SMO or CK2 in the SHH subgroup (A), targeting MYC-driven group 3 medulloblastoma using combination therapy with HDAC inhibitors and PI3K pathway inhibition (B) or BET-bromodomain inhibition to downregulate MYC expression (C), LSD1 inhibition in group 3 and group 4 medulloblastoma with GFI1/GFl1B overexpression (D), and CDK4/6 inhibition in non-WNT medulloblastoma (E). Copyright Azuravesta Design. Published with permission. Figure is available in color online only.

therapies that target this paramount clinical problem. Preclinical studies have demonstrated that metastatic medulloblastoma, like recurrent medulloblastoma, contains distinct molecular events compared to those of the primary tumor and have identified potential driver pathways, such as the PI3K signaling pathway. ${ }^{69,71}$ Another recent study has shed doubt on the dogma that medulloblastoma metastasizes to the leptomeninges exclusively via transit through the cerebrospinal fluid, suggesting a potential hematogenous route for metastatic spread..$^{15}$ Investigations that further characterize the mechanisms of metastasis may provide rational treatment targets for this high-risk disease. Numerous emerging technologies will allow for characterization of the tumor microenvironment in the metastatic niche, providing insights into how tumor cell interactions with other cell types support survival in the leptomeningeal space.

\section{Priorities for the Next Generation of Clinical Trials}

Given the overall rarity of medulloblastoma combined with the ever-increasing refinement of the molecular stratification of this disease, great coordination and planning are required so that upcoming trials are designed to strategically leverage the wealth of knowledge that our molecular understanding of this disorder has provided. Trials should incorporate not only subgroup information but also key genetic, cytogenetic, and epigenetic signatures that can predict outcome or suggest rational treatment targets. Additionally, trial outcomes must be carefully designed to effectively study this diverse disease entity. For example, the prospect of treatment de-escalation could be applied to the low-risk nonmetastatic group 4 tumors with chromosome 11 loss. ${ }^{50}$ However, given that group 4 medulloblastoma can recur more than 5 years after initial diagnosis, such a study would require longer-term follow-up for appropriate survival analysis. ${ }^{51}$ High-risk subgroups and subtypes must be prioritized for treatment intensification given the urgent need to improve outcomes for these patients, such as SHH patients with TP53 mutation and non-WNT patients with metastatic disease. ${ }^{50}$ Numerous preclinical studies have identified potential strategies to implement for these high-risk patients, including combination therapy with PI3K pathway inhibitors and histone deacetylase inhibitors or BET-bromodomain inhibitors for $M Y C$-driven group 3 medulloblastoma, targeting LSD1 in medulloblastoma with $G F I 1 / G F I 1 B$ over-activation, CDK inhibitors, and cell cycle checkpoint inhibitors (Fig. 5).,10,29,45 Given that metastatic disease is a key risk factor for treatment failure, the upfront addition of novel agents to current first-line treatments must be considered, rather than initiating these treatments after disease recurrence or progression. Trials of treatments for medul- 
loblastoma recurrence incorporating precision medicine approaches must consider re-biopsy of the tumor to ensure the correct targeted agent is selected, especially given the temporal and spatial heterogeneity of medulloblastoma. . $^{34,71}$ Finally, quality of life should be carefully examined so that a more precise understanding of how new interventions are changing patient outcomes can be reached.

\section{Acknowledgments}

We thank Azuravesta Rastan (Azuravesta Biomedical Design) for assistance in the preparation and design of the figures in this paper.

Dr. Taylor is supported by the NIH (R01CA148699 and R01CA159859), Pediatric Brain Tumor Foundation, Terry Fox Research Institute, Canadian Institutes of Health Research, CureSearch Foundation, b.r.a.i.n.child, Meagan's Walk, The Swifty Foundation, Genome Canada, Genome British Columbia, Genome Quebec, Ontario Research Fund, Worldwide Cancer Research, V Foundation for Cancer Research, and Ontario Institute for Cancer Research through funding provided by the Government of Ontario. Dr. Taylor is also supported by a Canadian Cancer Society Research Institute Impact grant and by a Stand Up To Cancer (SU2C) St. Baldrick's Pediatric Dream Team Translational Research Grant (SU2C-AACR-DT1113) and SU2C Canada Cancer Stem Cell Dream Team Research Funding (SU2C-AACRDT-19-15) provided by the Government of Canada through Genome Canada and the Canadian Institutes of Health Research, with supplementary support from the Ontario Institute for Cancer Research through funding provided by the Government of Ontario. Stand Up To Cancer is a program of the Entertainment Industry Foundation administered by the American Association for Cancer Research. Dr. Taylor is also supported by the Garron Family Chair in Childhood Cancer Research at The Hospital for Sick Children and the University of Toronto. Dr. Juraschka is supported by the Canadian Institutes of Health Research Vanier Canada Graduate Scholarships, the University of Toronto Clinician Investigator Program, and the University of Toronto SurgeonScientist Training Program.

\section{References}

1. Albright AL, Wisoff JH, Zeltzer PM, Boyett JM, Rorke LB, Stanley P: Effects of medulloblastoma resections on outcome in children: a report from the Children's Cancer Group. Neurosurgery 38:265-271, 1996

2. Bailey P, Cushing H: A Classification of the Tumors of the Glioma Group on a Histogenetic Basis With a Correlated Study of Prognosis. Philadelphia: JB Lippincott Company, 1926

3. Balter-Seri J, Mor C, Shuper A, Zaizov R, Cohen IJ: Cure of recurrent medulloblastoma: the contribution of surgical resection at relapse. Cancer 79:1241-1247, 1997

4. Bandopadhayay P, Bergthold G, Nguyen B, Schubert S, Gholamin S, Tang Y, et al: BET bromodomain inhibition of MYCamplified medulloblastoma. Clin Cancer Res 20:912-925, 2014

5. Bautista F, Fioravantti V, de Rojas T, Carceller F, Madero L, Lassaletta A, et al: Medulloblastoma in children and adolescents: a systematic review of contemporary phase I and II clinical trials and biology update. Cancer Med 6:26062624, 2017

6. Brugières L, Remenieras $A$, Pierron $G$, Varlet $P$, Forget $S$, Byrde V, et al: High frequency of germline SUFU mutations in children with desmoplastic/nodular medulloblastoma younger than 3 years of age. J Clin Oncol 30:2087-2093, 2012

7. Cavalli FMG, Remke M, Rampasek L, Peacock J, Shih DJH,
Luu B, et al: Intertumoral heterogeneity within medulloblastoma subgroups. Cancer Cell 31:737-754, 754.e1-754.e6, 2017

8. Cho YJ, Tsherniak A, Tamayo P, Santagata S, Ligon A, Greulich $\mathrm{H}$, et al: Integrative genomic analysis of medulloblastoma identifies a molecular subgroup that drives poor clinical outcome. J Clin Oncol 29:1424-1430, 2011

9. Clifford SC, Lusher ME, Lindsey JC, Langdon JA, Gilbertson RJ, Straughton D, et al: Wnt/Wingless pathway activation and chromosome 6 loss characterize a distinct molecular sub-group of medulloblastomas associated with a favorable prognosis. Cell Cycle 5:2666-2670, 2006

10. Cook Sangar ML, Genovesi LA, Nakamoto MW, Davis MJ, Knobluagh SE, Ji P, et al: Inhibition of CDK4/6 by palbociclib significantly extends survival in medulloblastoma patient-derived xenograft mouse models. Clin Cancer Res 23:5802-5813, 2017

11. Cushing H: Experiences with the cerebellar medulloblastomas. Acta Pathol Microbiol Scand 7:1-86, 1930

12. Gajjar A, Chintagumpala M, Ashley D, Kellie S, Kun LE, Merchant TE, et al: Risk-adapted craniospinal radiotherapy followed by high-dose chemotherapy and stem-cell rescue in children with newly diagnosed medulloblastoma (St Jude Medulloblastoma-96): long-term results from a prospective, multicentre trial. Lancet Oncol 7:813-820, 2006

13. Gajjar A, Pizer B: Role of high-dose chemotherapy for recurrent medulloblastoma and other CNS primitive neuroectodermal tumors. Pediatr Blood Cancer 54:649-651, 2010

14. Gandola L, Massimino M, Cefalo G, Solero C, Spreafico F, Pecori E, et al: Hyperfractionated accelerated radiotherapy in the Milan strategy for metastatic medulloblastoma. J Clin Oncol 27:566-571, 2009

15. Garzia L, Kijima N, Morrissy AS, De Antonellis P, Guerreiro-Stucklin A, Holgado BL, et al: A hematogenous route for medulloblastoma leptomeningeal metastases. Cell 172:1050-1062, 1062.e1-1062.e14, 2018

16. Hart MN, Earle KM: Primitive neuroectodermal tumors of the brain in children. Cancer 32:890-897, 1973

17. Huang GH, Xu QF, Cui YH, Li N, Bian XW, Lv SQ: Medulloblastoma stem cells: promising targets in medulloblastoma therapy. Cancer Sci 107:583-589, 2016

18. Jakacki RI, Burger PC, Zhou T, Holmes EJ, Kocak M, Onar A, et al: Outcome of children with metastatic medulloblastoma treated with carboplatin during craniospinal radiotherapy: a Children's Oncology Group Phase I/II study. J Clin Oncol 30:2648-2653, 2012

19. Janku F, Yap TA, Meric-Bernstam F: Targeting the PI3K pathway in cancer: are we making headway? Nat Rev Clin Oncol 15:273-291, 2018

20. Johnston DL, Keene D, Kostova M, Lafay-Cousin L, Fryer C, Scheinemann K, et al: Survival of children with medulloblastoma in Canada diagnosed between 1990 and 2009 inclusive. J Neurooncol 124:247-253, 2015

21. Johnston DL, Keene D, Strother D, Taneva M, Lafay-Cousin L, Fryer C, et al: Survival following tumor recurrence in children with medulloblastoma. J Pediatr Hematol Oncol 40:e159-e163, 2018

22. Jones DTW, Jäger N, Kool M, Zichner T, Hutter B, Sultan M, et al: Dissecting the genomic complexity underlying medulloblastoma. Nature 488:100-105, 2012

23. Kaatsch P, Grabow D, Spix C: German Childhood Cancer Registry Annual Report 2016. Mainz, Germany: Institut für Medizinische Biometrie, Epidemiologie und Informatik (IMBEI), Universitätsmedizin der Johannes GutenbergUniversität Mainz, 2017 (http://www.kinderkrebsregister.de/ typo3temp/secure_downloads/22605/0/17aa97a18ea4a83442 4f1eb1a46e6ada9829b582/jb2016_s.pdf) [Accessed June 18, 2019]

24. Kool M, Korshunov A, Remke M, Jones DTW, Schlanstein 
M, Northcott PA, et al: Molecular subgroups of medulloblastoma: an international meta-analysis of transcriptome, genetic aberrations, and clinical data of WNT, SHH, Group 3 , and Group 4 medulloblastomas. Acta Neuropathol 123:473-484, 2012

25. Kool M, Koster J, Bunt J, Hasselt NE, Lakeman A, van Sluis $\mathrm{P}$, et al: Integrated genomics identifies five medulloblastoma subtypes with distinct genetic profiles, pathway signatures and clinicopathological features. PLoS One 3:e3088, 2008

26. Kunschner LJ: Harvey Cushing and medulloblastoma. Arch Neurol 59:642-645, 2002

27. Laubach JP, Moreau P, San-Miguel JF, Richardson PG: Panobinostat for the treatment of multiple myeloma. Clin Cancer Res 21:4767-4773, 2015

28. Law N, Greenberg M, Bouffet E, Taylor MD, Laughlin S, Strother D, et al: Clinical and neuroanatomical predictors of cerebellar mutism syndrome. Neuro Oncol 14:1294-1303, 2012

29. Lee C, Rudneva VA, Erkek S, Zapatka M, Chau LQ, Tacheva-Grigorova SK, et al: Lsd1 as a therapeutic target in Gfilactivated medulloblastoma. Nat Commun 10:332, 2019

30. LoRusso PM, Rudin CM, Reddy JC, Tibes R, Weiss GJ, Borad MJ, et al: Phase I trial of hedgehog pathway inhibitor vismodegib (GDC-0449) in patients with refractory, locally advanced or metastatic solid tumors. Clin Cancer Res 17:2502-2511, 2011

31. Louis DN, Perry A, Reifenberger G, von Deimling A, Figarella-Branger D, Cavenee WK, et al: The 2016 World Health Organization Classification of Tumors of the Central Nervous System: a summary. Acta Neuropathol 131:803-820, 2016

32. Millard NE, De Braganca KC: Medulloblastoma. J Child Neurol 31:1341-1353, 2016

33. Möröy T, Vassen L, Wilkes B, Khandanpour C: From cytopenia to leukemia: the role of Gfil and Gfilb in blood formation. Blood 126:2561-2569, 2015

34. Morrissy AS, Garzia L, Shih DJH, Zuyderduyn S, Huang X, Skowron P, et al: Divergent clonal selection dominates medulloblastoma at recurrence. Nature 529:351-357, 2016

35. Moxon-Emre I, Taylor MD, Bouffet E, Hardy K, Campen CJ, Malkin D, et al: Intellectual outcome in molecular subgroups of medulloblastoma. J Clin Oncol 34:4161-4170, 2016

36. Northcott PA, Buchhalter I, Morrissy AS, Hovestadt V, Weischenfeldt J, Ehrenberger T, et al: The whole-genome landscape of medulloblastoma subtypes. Nature 547:311317,2017

37. Northcott PA, Korshunov A, Witt H, Hielscher T, Eberhart CG, Mack S, et al: Medulloblastoma comprises four distinct molecular variants. J Clin Oncol 29:1408-1414, 2011

38. Northcott PA, Lee C, Zichner T, Stütz AM, Erkek S, Kawauchi D, et al: Enhancer hijacking activates GFI1 family oncogenes in medulloblastoma. Nature 511:428-434, 2014

39. Northcott PA, Shih DJH, Peacock J, Garzia L, Morrissy AS, Zichner T, et al: Subgroup-specific structural variation across 1,000 medulloblastoma genomes. Nature 488:49-56, 2012

40. Ostrom QT, Gittleman H, Truitt G, Boscia A, Kruchko C, Barnholtz-Sloan JS: CBTRUS statistical report: primary brain and other central nervous system tumors diagnosed in the United States in 2011-2015. Neuro Oncol 20 (Suppl 4):iv1-iv86, 2018

41. Packer RJ, Gajjar A, Vezina G, Rorke-Adams L, Burger PC, Robertson PL, et al: Phase III study of craniospinal radiation therapy followed by adjuvant chemotherapy for newly diagnosed average-risk medulloblastoma. J Clin Oncol 24:42024208, 2006

42. Packer RJ, Vezina G: Management of and prognosis with medulloblastoma: therapy at a crossroads. Arch Neurol 65:1419-1424, 2008

43. Packer RJ, Zhou T, Holmes E, Vezina G, Gajjar A: Survival and secondary tumors in children with medulloblastoma receiving radiotherapy and adjuvant chemotherapy: results of Children's Oncology Group trial A9961. Neuro Oncol 15:97-103, 2013

44. Paterson E, Farr RF: Cerebellar medulloblastoma: treatment by irradiation of the whole central nervous system. Acta Radiol 39:323-336, 1953

45. Pei Y, Liu KW, Wang J, Garancher A, Tao R, Esparza LA, et al: HDAC and PI3K antagonists cooperate to inhibit growth of MYC-driven medulloblastoma. Cancer Cell 29:311-323, 2016

46. Perreault S, Ramaswamy V, Achrol AS, Chao K, Liu TT, Shih D, et al: MRI surrogates for molecular subgroups of medulloblastoma. AJNR Am J Neuroradiol 35:1263-1269, 2014

47. Pomeroy SL, Tamayo P, Gaasenbeek M, Sturla LM, Angelo M, McLaughlin ME, et al: Prediction of central nervous system embryonal tumour outcome based on gene expression. Nature 415:436-442, 2002

48. Pugh TJ, Weeraratne SD, Archer TC, Pomeranz Krummel DA, Auclair D, Bochicchio J, et al: Medulloblastoma exome sequencing uncovers subtype-specific somatic mutations. Nature 488:106-110, 2012

49. Purzner T, Purzner J, Buckstaff T, Cozza G, Gholamin S, Rusert JM, et al: Developmental phosphoproteomics identifies the kinase CK2 as a driver of Hedgehog signaling and a therapeutic target in medulloblastoma. Sci Signal 11:eaau5147, 2018

50. Ramaswamy V, Remke M, Bouffet E, Bailey S, Clifford SC, Doz F, et al: Risk stratification of childhood medulloblastoma in the molecular era: the current consensus. Acta Neuropathol 131:821-831, 2016

51. Ramaswamy V, Remke M, Bouffet E, Faria CC, Perreault S, Cho YJ, et al: Recurrence patterns across medulloblastoma subgroups: an integrated clinical and molecular analysis. Lancet Oncol 14:1200-1207, 2013

52. Remke M, Hielscher T, Northcott PA, Witt H, Ryzhova M, Wittmann A, et al: Adult medulloblastoma comprises three major molecular variants. J Clin Oncol 29:2717-2723, 2011

53. Ribi K, Relly C, Landolt MA, Alber FD, Boltshauser E, Grotzer MA: Outcome of medulloblastoma in children: longterm complications and quality of life. Neuropediatrics 36:357-365, 2005

54. Robinson G, Parker M, Kranenburg TA, Lu C, Chen X, Ding L, et al: Novel mutations target distinct subgroups of medulloblastoma. Nature 488:43-48, 2012

55. Robinson GW, Orr BA, Wu G, Gururangan S, Lin T, Qaddoumi I, et al: Vismodegib exerts targeted efficacy against recurrent Sonic hedgehog-subgroup medulloblastoma: results from phase II Pediatric Brain Tumor Consortium studies PBTC-025B and PBTC-032. J Clin Oncol 33:2646-2654, 2015

56. Robinson GW, Rudneva VA, Buchhalter I, Billups CA, Waszak SM, Smith KS, et al: Risk-adapted therapy for young children with medulloblastoma (SJYC07): therapeutic and molecular outcomes from a multicentre, phase 2 trial. Lancet Oncol 19:768-784, 2018

57. Rutka JT, Hoffman HJ: Medulloblastoma: a historical perspective and overview. J Neurooncol 29:1-7, 1996

58. Rutkowski S, Bode U, Deinlein F, Ottensmeier H, WarmuthMetz M, Soerensen N, et al: Treatment of early childhood medulloblastoma by postoperative chemotherapy alone. $\mathbf{N}$ Engl J Med 352:978-986, 2005

59. Schwalbe EC, Lindsey JC, Nakjang S, Crosier S, Smith AJ, Hicks D, et al: Novel molecular subgroups for clinical classification and outcome prediction in childhood medulloblastoma: a cohort study. Lancet Oncol 18:958-971, 2017

60. Taylor MD, Liu L, Raffel C, Hui CC, Mainprize TG, Zhang $\mathrm{X}$, et al: Mutations in SUFU predispose to medulloblastoma. Nat Genet 31:306-310, 2002 
61. Taylor MD, Northcott PA, Korshunov A, Remke M, Cho YJ, Clifford SC, et al: Molecular subgroups of medulloblastoma: the current consensus. Acta Neuropathol 123:465-472, 2012

62. Thompson EM, Hielscher T, Bouffet E, Remke M, Luu B, Gururangan S, et al: Prognostic value of medulloblastoma extent of resection after accounting for molecular subgroup: a retrospective integrated clinical and molecular analysis. Lancet Oncol 17:484-495, 2016

63. Thompson MC, Fuller C, Hogg TL, Dalton J, Finkelstein D, Lau CC, et al: Genomics identifies medulloblastoma subgroups that are enriched for specific genetic alterations. J Clin Oncol 24:1924-1931, 2006

64. Twigg SRF, Hufnagel RB, Miller KA, Zhou Y, McGowan SJ, Taylor J, et al: A recurrent mosaic mutation in SMO, encoding the hedgehog signal transducer smoothened, is the major cause of Curry-Jones syndrome. Am J Hum Genet 98:12561265,2016

65. VanArsdale T, Boshoff C, Arndt KT, Abraham RT: Molecular pathways: targeting the cyclin D-CDK4/6 axis for cancer treatment. Clin Cancer Res 21:2905-2910, 2015

66. Veneroni L, Boschetti L, Barretta F, Clerici CA, Simonetti F, Schiavello E, et al: Quality of life in long-term survivors treated for metastatic medulloblastoma with a hyperfractionated accelerated radiotherapy (HART) strategy. Childs Nerv Syst 33:1969-1976, 2017

67. Vladoiu MC, El-Hamamy I, Donovan LK, Farooq H, Holgado BL, Sundaravadanam Y, et al: Childhood cerebellar tumours mirror conserved fetal transcriptional programs. Nature [epub ahead of print], 2019

68. von Bueren AO, Kortmann RD, von Hoff K, Friedrich C, Mynarek M, Müller K, et al: Treatment of children and adolescents with metastatic medulloblastoma and prognostic relevance of clinical and biologic parameters. J Clin Oncol 34:4151-4160, 2016

69. Wang X, Dubuc AM, Ramaswamy V, Mack S, Gendoo DMA, Remke M, et al: Medulloblastoma subgroups remain stable across primary and metastatic compartments. Acta Neuropathol 129:449-457, 2015
70. Waszak SM, Northcott PA, Buchhalter I, Robinson GW, Sutter C, Groebner S, et al: Spectrum and prevalence of genetic predisposition in medulloblastoma: a retrospective genetic study and prospective validation in a clinical trial cohort. Lancet Oncol 19:785-798, 2018

71. Wu X, Northcott PA, Dubuc A, Dupuy AJ, Shih DJH, Witt H, et al: Clonal selection drives genetic divergence of metastatic medulloblastoma. Nature 482:529-533, 2012

72. Yock TI, Yeap BY, Ebb DH, Weyman E, Eaton BR, Sherry NA, et al: Long-term toxic effects of proton radiotherapy for paediatric medulloblastoma: a phase 2 single-arm study. Lancet Oncol 17:287-298, 2016

73. Zhu H, Bengsch F, Svoronos N, Rutkowski MR, Bitler BG, Allegrezza MJ, et al: BET bromodomain inhibition promotes anti-tumor immunity by suppressing PD-L1 expression. Cell Reports 16:2829-2837, 2016

\section{Disclosures}

The authors report no conflict of interest concerning the materials or methods used in this study or the findings specified in this paper.

\section{Author Contributions}

Conception and design: both authors. Acquisition of data: both authors. Analysis and interpretation of data: both authors. Drafting the article: both authors. Critically revising the article: both authors. Reviewed submitted version of manuscript: both authors. Approved the final version of the manuscript on behalf of both authors: Taylor. Administrative/technical/material support: Taylor. Study supervision: Taylor.

\section{Correspondence}

Michael D. Taylor: The Hospital for Sick Children, Toronto, ON, Canada.mdtaylor@sickkids.ca. 